\title{
EXTRAÇÃO DE ÓLEO DO RESÍDUO DE TAMBATINGA (Colossoma macropomum x Piaractus brachypomus, Characidae) EMPREGANDO TECNOLOGIA ULTRASSÔNICA
}

Débora Silva da Rocha ${ }^{1}$, César Vinicius Toniciolli Rigueto ${ }^{2^{*}}$, Thainá Stéphanie Martins de Freitas ${ }^{3}$, Raquel Aparecida Loss ${ }^{4}$, Claudineia Aparecida Queli Geraldi ${ }^{5}$

${ }^{1,2,3}$ Bacharéis em Engenharia de Alimentos - Universidade do Estado de Mato Grosso (UNEMAT)

${ }^{4,5}$ Docentes do curso de Engenharia de Alimentos - Universidade do Estado de Mato Grosso (UNEMAT).

E-mail principal: cesartoniciolli@gmail.com

Recebido em: 06/04/2019 - Aprovado em: 10/06/2019 - Publicado em: 30/06/2019 DOI: 10.18677/EnciBio_2019A67

\begin{abstract}
RESUMO
O aumento na demanda do consumo de pescados acarreta na geração de uma maior quantidade de resíduos, com expressivos danos ao meio ambiente. Assim, a busca por alternativas de reuso desta carga orgânica é essencial para atingir o equilíbrio ecológico. Além disso, esses resíduos são ricos em compostos benéficos ao organismo humano, como os ácidos graxos poli-insaturados. Desta forma, o objetivo desta pesquisa foi avaliar a extração de óleo do resíduo de tambatinga por energia ultrassônica. A extração do óleo foi avaliada empregando a matéria prima úmida e seca a $100^{\circ} \mathrm{C}$, a partir de um Delineamento Composto Central Rotacional $2^{2}$, onde as variáveis foram razão amostra: solvente e tempo. O óleo obtido na condição de extração que permitiu o maior rendimento em óleo foi submetido ao perfil de ácidos graxos por cromatografia gasosa. Na extração de óleo, as amostras

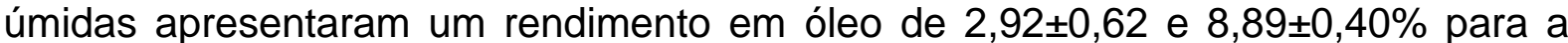
amostra úmida e seca a $100^{\circ} \mathrm{C}$, respectivamente, indicando que o processo de secagem interfere no rendimento da extração. Diante disto, conclui-se que a extração de óleo empregando a energia ultrassônica é um método eficaz para obtenção de óleo, visto que este método pode contribuir para a redução do tempo de extração.
\end{abstract}

PALAVRAS-CHAVE: Ômega-3; Peixe; Secagem; Ultrassom.

\section{TAMBATINGA WASTE OIL EXTRACTION (Colossoma macropomum $x$ Piaractus brachypomus, Characidae) EMPLOYING ULTRASONIC TECHNOLOGY}

\section{ABSCTRACT}

The increase in demand for fish consumption leads to the generation of a greater amount of waste, with significant damages to the environment. Thus, the search for alternatives of reuse of this organic load is essential to achieve the ecological balance. In addition, these residues are rich in compounds beneficial to the human 
body, such as polyunsaturated fatty acids. In this way, the objective of this research was to evaluate the oil extraction of the tambatinga residue by ultrasonic energy. The extraction of the oil was evaluated using a wet and dry raw material at $100^{\circ} \mathrm{C}$, from a Rotational Central Compound $2^{2}$ Design, where the variables were sample: solvent ratio and time. The oil obtained in the extraction condition that allowed the highest yield in oil was submitted to the fatty acid profile by gas chromatography. In the oil extraction, the wet samples had an oil yield of $2.92 \pm 0.62$ and $8.89 \pm 0.40 \%$ for the wet sample and dried at $100^{\circ} \mathrm{C}$, respectively, indicating that the drying process interferes in the extraction yield. Therefore, it is concluded that the extraction of oil using ultrasonic energy is an efficient method to obtain oil, since this method can contribute to the reduction of extraction time.

KEYWORDS: Ômega-3; Fish; Drying; Ultrasound.

\section{INTRODUÇÃO}

Os pescados se destacam por serem considerados excelentes fontes de proteínas, ácidos graxos e minerais (GONÇALVES; SOARES, 2012). Porém, com o aumento da demanda consumidora, a quantidade de resíduos provenientes de indústrias processadoras de pescado cresce em igual e/ou maior proporção (MONTEIRO, 2013). Segundo Decker et al. (2016) o livre descarte dos resíduos dessa atividade no meio ambiente bem como a contaminação direta dos recursos hídricos e dos solos acarreta em danos exponencialmente perigosos ao equilíbrio ecológico.

Esses resíduos possuem valor agregado relativamente baixo, como cabeça, barbatanas, pele, vísceras e escamas, podendo ser utilizados de forma adequada, proporcionando renda extra para os pescadores ou para os estabelecimentos de processamento, além de minimizar o impacto ao meio ambiente (MARTINS et al., 2014).

Segundo a Associação Brasileira da Piscicultura, em 2017, a produção brasileira de pescado foi de 691,7 mil toneladas, sendo que o Estado de Mato Grosso produziu 62 mil toneladas, ocupando a 4⿳亠丷⿵冂⿱⺊口灬 posição do ranking dos maiores produtores de peixes do Brasil. Entre as espécies mais criadas estão a tilápia, tambaqui, tambacu e tambatinga (ABP, 2017).

A linha tênue entre sustentabilidade e o desenvolvimento científico é a busca por soluções e métodos que sejam satisfatórios para a construção do conhecimento, a chamada "química verde", tem se preocupado em traçar metas para o desenvolvimento eficaz da ciência. $O$ uso do ultrassom para extração de óleo é um exemplo da aplicação de técnicas relacionadas ao desenvolvimento sustentável, uma vez que este método é considerado menos poluente por relacionar dois quesitos básicos para obtenção do óleo: menor tempo de extração e quantidade reduzida de solvente (TSUKUI; REZENDE, 2014).

Desta forma, o presente trabalho teve por objetivo, obter óleo a partir de resíduos de tambatinga, avaliando as melhores condições operacionais na extração empregando energia ultrassônica e, avaliando o óleo em função do perfil de ácidos graxos.

\section{MATERIAL E MÉTODOS}

Os resíduos de tambatinga $(10 \mathrm{~kg})$ foram adquiridos junto a pescadores no munícipio de Barra do Bugres-MT, acondicionados em ambiente refrigerado. Os resíduos foram constituídos principalmente por cabeça, espinhaço, nadadeiras, 
couro, escamas e calda, que foram triturados com o auxílio de um liquidificador industrial e armazenados sob congelamento até o momento das análises.

\section{Cinética de secagem e modelagem matemática}

Para obter a cinética de secagem e avaliar a influência da temperatura na qualidade final do óleo, os $10 \mathrm{~kg}$ de resíduos foram divididos em cinco partes iguais e submetidos a secagem em estufa com circulação forçada de ar, nas temperaturas de $50,60,70$ e $100^{\circ} \mathrm{C}$. Foram colocadas $10 \mathrm{~g}$ de massa de resíduo em cada placa de Petri previamente seca. Acompanhou-se a perda de umidade pela variação da massa das amostras em intervalos de tempo de 15 minutos, a secagem foi encerrada após obter massa constante. Todo o processo de secagem, foi realizado em triplicata para cada temperatura em estudo $\left(50,60,70\right.$ e $\left.100^{\circ} \mathrm{C}\right)$. A razão de umidade $(\mathrm{RU})$ foi determinada pela Equação 1.

$$
R U=\frac{(U-U e)}{(U i-U e)}
$$

Onde: $\mathrm{U}=$ teor de água do produto, decimal b.s; $\mathrm{Ui}=$ teor de água inicial do produto, decimal b.s; Ue= teor de água de equilíbrio do produto, decimal b.s.

Para a representação das curvas de secagem, foram utilizados três modelos matemáticos empíricos (Tabela 1) comumente usados para a representação dos dados de secagem, sendo que a escolha do modelo que melhor se ajustou aos dados experimentais foi feita em função da correlação e do erro padrão médio.

TABELA 1. Modelos matemáticos empregados na representação da cinética de secagem

Modelo

Equação

Page

$$
R U=\exp \left(-k * t^{n}\right)
$$

Henderson e Pabis

$R U=a \exp (-k * t)$

Midilli e Kucuk

$R U=a \exp \left(-k * t^{n}\right) b * t$

$\overline{\mathrm{RU}}=$ razão do teor de água do produto, adimensional; $\mathrm{t}=$ tempo de secagem, em $\mathrm{h}$;

$\mathrm{k}=$ coeficiente de secagem, em s $\mathrm{s}^{-1} ; \mathrm{a}, \mathrm{b}$ e $\mathrm{n}=$ constantes dos modelos, adimensional.

\section{Extração em banho ultrassônico}

Nos ensaios de extração em banho ultrassônico foram utilizadas apenas as amostras de resíduo de peixe úmidas (in natura) e secas a $100^{\circ} \mathrm{C}$. As condições de extração variaram conforme o planejamento Composto Central Rotacional $2^{2}$, onde 
as variáveis foram razão entre a quantidade de resíduo e solvente e o tempo de extração (Tabela 2).

Os ensaios de extração foram incubados em banho ultrassônico (Quimis, Q335D), com uma frequência de $40 \mathrm{kHz}$, conectado a um condensador. Ao final do processo de extração o excesso de solvente foi recuperado em sistema Soxhlet a $70^{\circ} \mathrm{C}$ e evaporado em estufa também a $70^{\circ} \mathrm{C}$ até massa constante.

TABELA 2. Variáveis e níveis estudados no Planejamento Composto Central Rotacional $2^{2}$ na extração de óleo de resíduo de tambatinga

\begin{tabular}{ccc} 
Níveis & \multicolumn{2}{c}{ Variáveis } \\
\cline { 2 - 3 } & $\begin{array}{c}\text { Resíduo:Solvente } \\
\text { (g:mL) }\end{array}$ & $\begin{array}{c}\text { Tempo } \\
\text { (min) }\end{array}$ \\
\hline$+1,41$ & $1: 5$ & 70 \\
+1 & $1: 4$ & 60 \\
0 & $1: 3$ & 40 \\
-1 & $1: 2$ & 20 \\
$-1,41$ & $1: 1$ & 12 \\
\hline
\end{tabular}

Os resultados do planejamento experimental foram expressos em termos de rendimento de extração e, submetidos a análise estatística no software Assistat 7.7. A determinação do teor de óleo extraído foi feita pela diferença de massa entre o peso da amostra inicial e o peso da amostra final após a extração e evaporação do solvente.

Para expressar os resultados, os dados foram transformados em percentagem em relação ao peso inicial da amostra. O óleo obtido nas condições que melhor favoreceram o processo de extração foi extraído novamente em um volume maior e submetido ao perfil de ácidos graxos.

\section{Perfil de ácidos graxos}

Para o perfil de ácidos graxos, os ésteres metílicos de ácidos graxos foram analisados em cromatógrafo gasoso (Varian, 33800, equipado com um detector de ionização de chama e coluna capilar de sílica fundida CP - 7420 (Select FAME) (100 $\mathrm{m}$ de comprimento, 0,25 mm de diâmetro interno e 0,25 $\mathrm{m}$ de cianopropil). O fluxo de $\mathrm{H}_{2}$ (gás de arraste) foi de 1,0 mL.min ${ }^{-1}$, com $30 \mathrm{~mL} \cdot \mathrm{min}^{-1}$ de $\mathrm{N}_{2}$ (make up); e 30 e $300 \mathrm{~mL}$. $\mathrm{min}^{-1}$, para $\mathrm{o} \mathrm{H}_{2}$ e ar sintético, para a chama do detector, respectivamente. $\mathrm{O}$ volume injetado foi de 2,0 L utilizando split 1:80, sendo as temperaturas do injetor e detector de 220 e $240{ }^{\circ} \mathrm{C}$, respectivamente, enquanto a coluna de $165^{\circ} \mathrm{C}$ durante 18 minutos e elevada a $235^{\circ} \mathrm{C}$ com taxa de $4^{\circ} \mathrm{C} \cdot \mathrm{min}^{-1}$, mantida por 14,5 minutos. Os resultados foram expressos em porcentagens ácidos graxos. 


\section{RESULTADOS E DISCUSSÃO}

O comportamento cinético das amostras submetidas a secagem a $50,60,70$ e $100^{\circ} \mathrm{C}$, são apresentados nas Figura 5 (a), (b), (c) e (d), respectivamente.

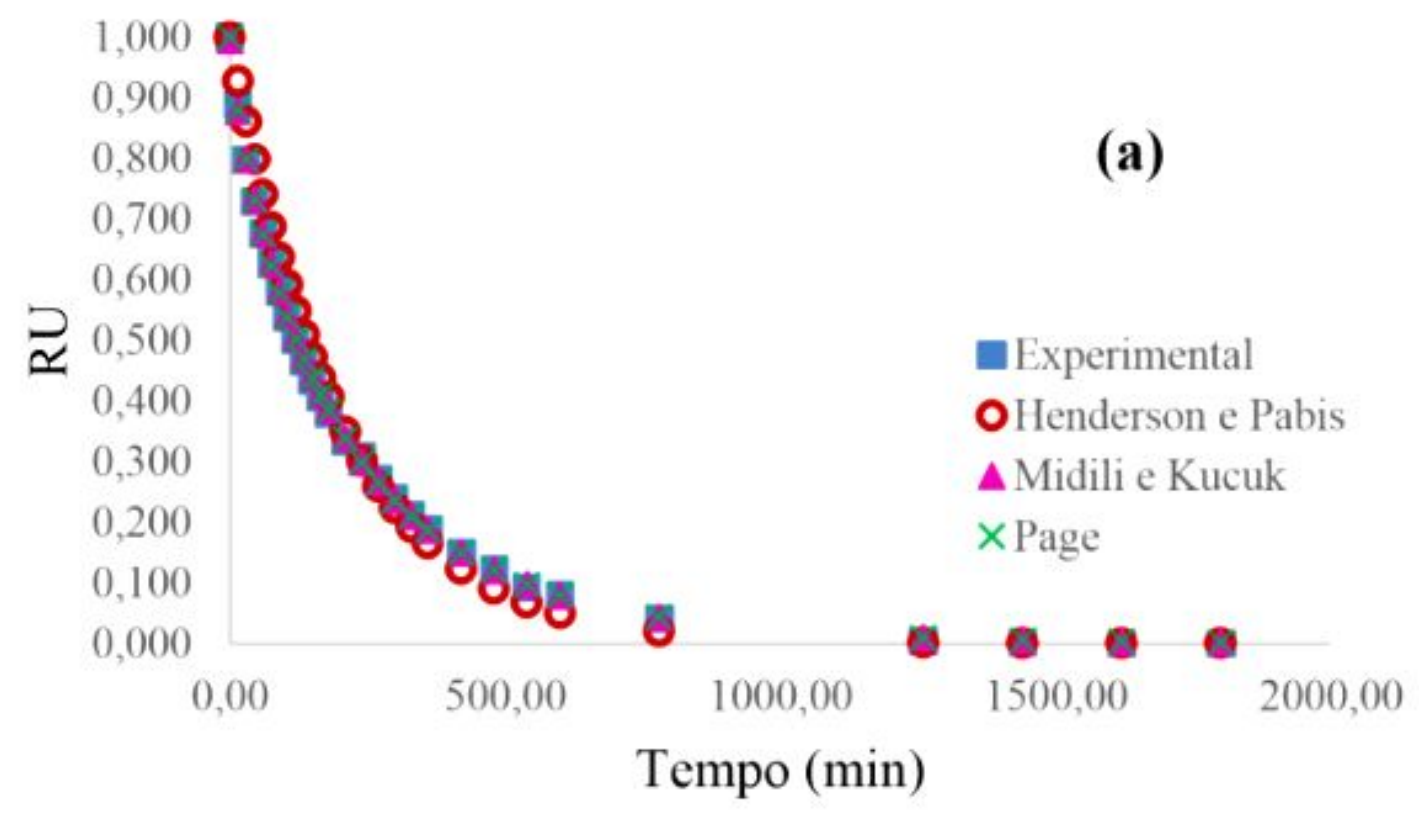

FIGURA 5 (a). Curvas de secagem do resíduo de tambatinga empregando diferentes modelos matemáticos na temperatura de $50^{\circ} \mathrm{C}$. Fonte: Autores (2018).

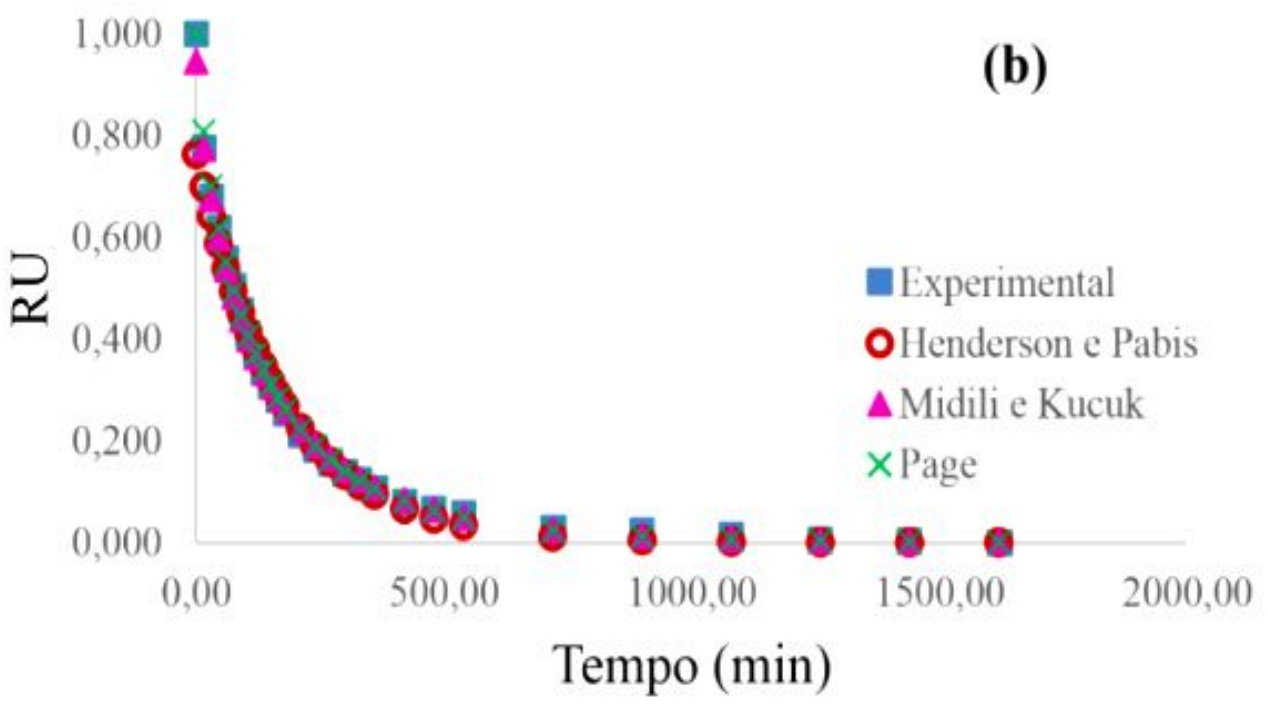

FIGURA 5 (b). Curvas de secagem do resíduo de tambatinga empregando diferentes modelos matemáticos na temperatura de $60^{\circ} \mathrm{C}$. Fonte: Autores (2018). 


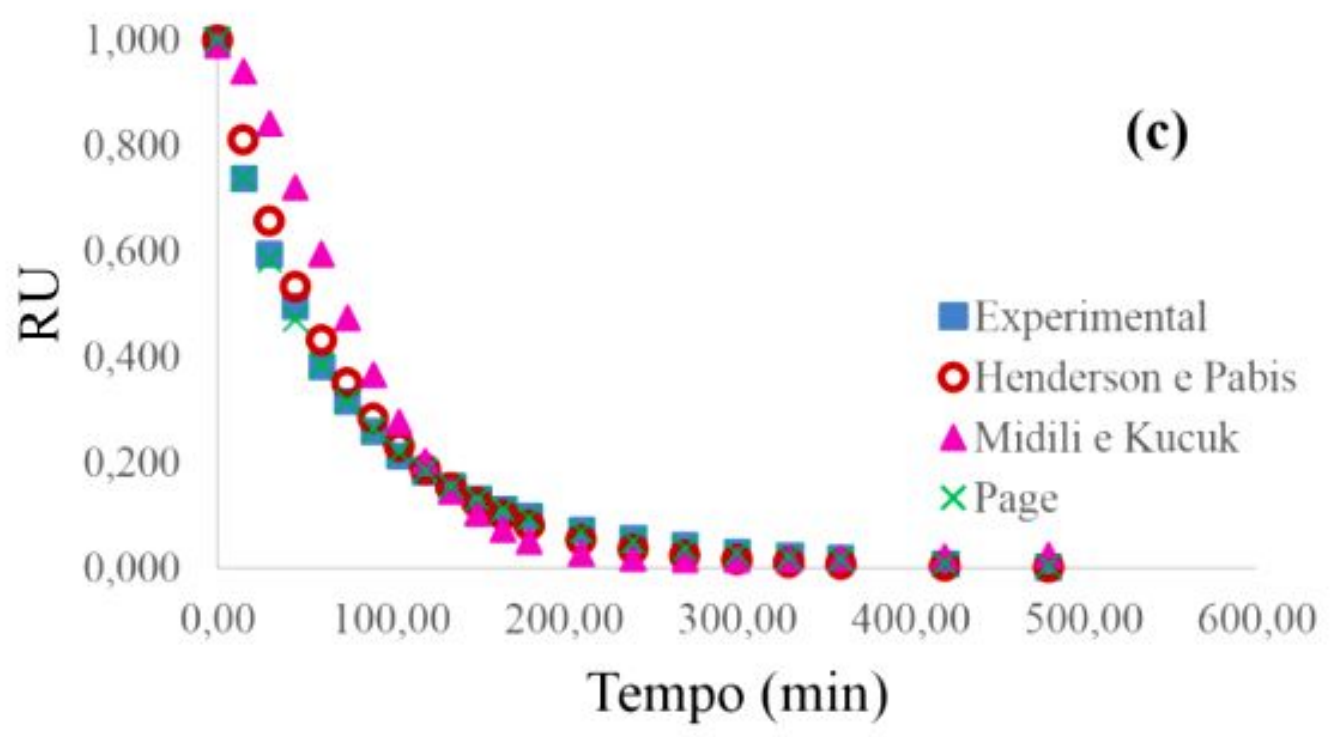

FIGURA 5 (c). Curvas de secagem do resíduo de tambatinga empregando diferentes modelos matemáticos na temperatura de $70^{\circ} \mathrm{C}$. Fonte: Autores (2018).

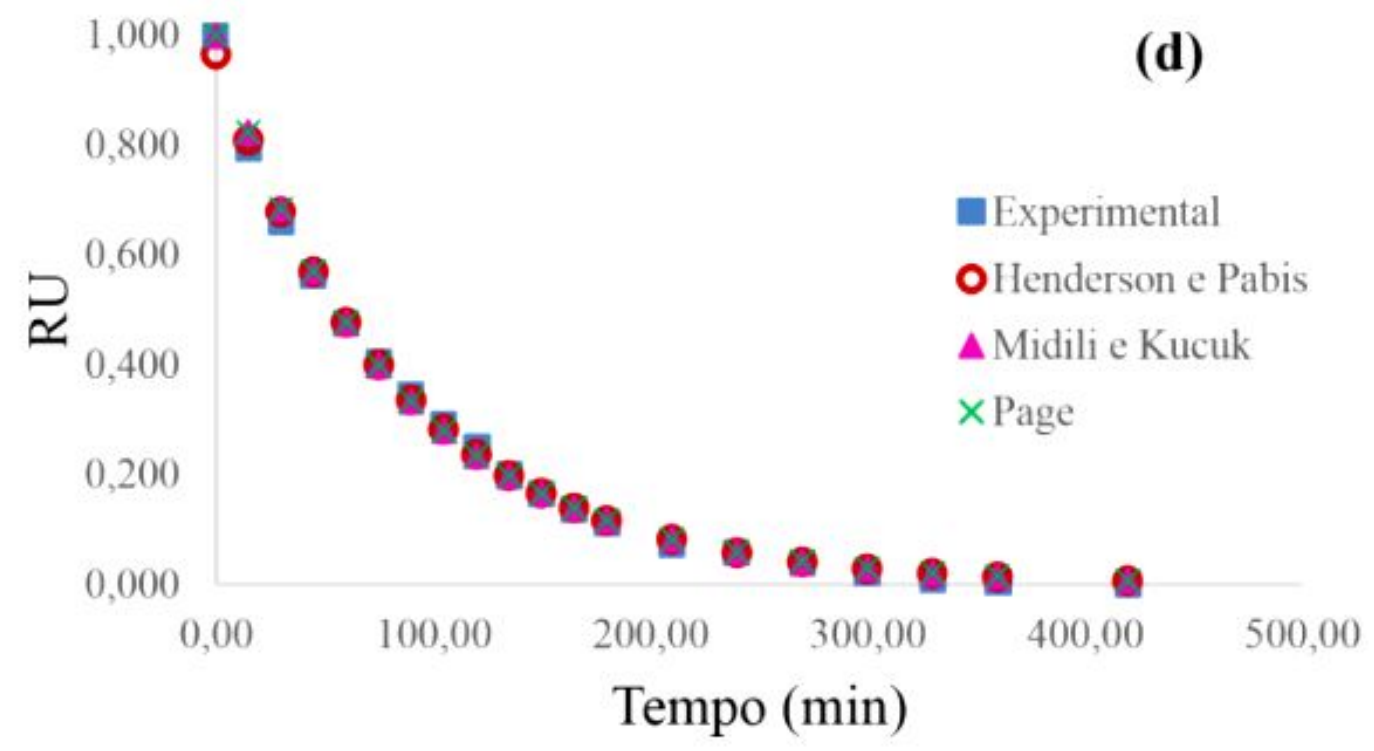

FIGURA 5 (d). Curvas de secagem do resíduo de tambatinga empregando diferentes modelos matemáticos na temperatura de $100^{\circ} \mathrm{C}$. Fonte: Autores (2018).

Pela análise das Figuras 5 (a), (b), (c) e (d), verificou-se que para a temperatura de $50^{\circ} \mathrm{C}$ o tempo necessário para atingir a umidade de equilíbrio foi de 1250 minutos, enquanto que a 60,70 e $100^{\circ} \mathrm{C}$ este tempo foi reduzido para 750,250 e 210 minutos, respectivamente. Portanto, quanto mais alta a temperatura, menor foi o tempo necessário para as amostras atingirem a umidade de equilíbrio.

Ainda, a Tabela 3 apresenta os valores dos parâmetros obtidos nos ajustes dos modelos matemáticos aos dados experimentais de secagem do resíduo de tambatinga em estufa com circulação forçada de ar. 
TABELA 3. Valores dos parâmetros dos modelos matemáticos empregados

\begin{tabular}{|c|c|c|c|c|c|}
\hline Modelo & Parâmetros & $50 \div \mathrm{C}$ & $60^{\circ} \mathrm{C}$ & $70^{\circ} \mathrm{C}$ & $100^{\circ} \mathrm{C}$ \\
\hline \multirow{4}{*}{$\begin{array}{l}\text { Henderson } \\
\text { e Pabis }\end{array}$} & a & 1,000000 & 0,763581 & 1,000000 & 0,964590 \\
\hline & k & 0,005000 & 0,005814 & 0,01400 & 0,011736 \\
\hline & Correlação & 0,997310 & 0,987322 & 0,997034 & 0,999140 \\
\hline & Erro & 5,907131 & 6,455897 & 12,542783 & 3,728994 \\
\hline \multirow{6}{*}{$\begin{array}{c}\text { Midilli e } \\
\text { Kucuk }\end{array}$} & $\mathrm{a}$ & 0,995687 & 0,945814 & 0,990000 & 0,999854 \\
\hline & b & 0,000000 & 0,000000 & 0,000050 & 0,000000 \\
\hline & $\mathrm{k}$ & 0,013787 & 0,026285 & 0,000600 & 0,014089 \\
\hline & $\mathrm{n}$ & 0,814894 & 0,749684 & 1,650000 & 0,967549 \\
\hline & Correlação & 0,999905 & 0,998961 & 0,967771 & 0,999365 \\
\hline & Erro & 1,107035 & 3,070694 & 9,463138 & 0,172375 \\
\hline \multirow{4}{*}{ Page } & $\mathrm{k}$ & 0,014517 & 0,028545 & 0,032826 & 0,014178 \\
\hline & $n$ & 0,806653 & 0,741595 & 0,823316 & 0,966314 \\
\hline & Correlaç & 0,999888 & 0,999559 & 0,999673 & 0,999272 \\
\hline & Erro & 1,102065 & 3,156902 & 8,092344 & 0,172773 \\
\hline
\end{tabular}

$\mathrm{Na}$ Tabela 3, ao analisar a correlação dos três modelos matemáticos empregados observa-se que para todas as temperaturas estudadas, os valores de correlação foram elevados, sugerindo um bom ajuste dos modelos aos dados experimentais. Em relação ao erro médio padrão, o modelo de Henderson e Pabis apresentou os maiores erros, enquanto que as equações propostas por Midilli e Kucuk e Page não diferiram significativamente entre si. Neste contexto, o modelo proposto por Page foi a equação que apresentou melhor ajuste em relação a correlação, erro e menor número de parâmetros.

\section{Extração em banho ultrassônico}

Estudos de Bevilaqua (2015), com a extração de óleo com resíduo de Pacu empregando a energia ultrassônica averiguou que a amostras submetidas a secagem nas maiores temperaturas, acarretaram maior rendimento de óleo. Desta forma, apenas as amostras secas a $100^{\circ} \mathrm{C}$ e as in natura foram submetidas ao processo de extração de óleo.

A Tabela 4 apresenta os rendimentos obtidos na extração do óleo de tambatinga empregando energia ultrassônica, sendo possível observar que a amostra seca apresentou rendimentos superiores aos obtidos com a amostra úmida. 
TABELA 4. Matriz do delineamento composto central rotacional $2^{2}$ para a extração de óleo de resíduo de tambatinga com amostra úmida e seca

\begin{tabular}{|c|c|c|c|c|c|c|}
\hline \multirow[b]{2}{*}{ Ensaios } & \multirow{2}{*}{$\begin{array}{c}\text { Proporção } \\
\text { Amostra:solvente } \\
\text { (g:mL) }\end{array}$} & \multirow[b]{2}{*}{$\begin{array}{c}\text { Tempo } \\
\text { (min) }\end{array}$} & \multirow{2}{*}{$\begin{array}{c}\text { In natura } \\
\begin{array}{c}\text { Óleo } \\
(\%)\end{array}\end{array}$} & \multicolumn{3}{|c|}{ Seca } \\
\hline & & & & $\begin{array}{c}\text { Óleo } \\
\text { Experimenta } \\
\text { I } \\
(\%)\end{array}$ & $\begin{array}{l}\text { Óleo } \\
\text { Predito } \\
(\%)\end{array}$ & Erro \\
\hline 1 & $1: 2(-1)$ & $20(-1)$ & 2,77 & 6,71 & 4,76 & 1,95 \\
\hline 2 & $1: 4(1)$ & $20(-1)$ & 3,22 & 8,46 & 7,40 & 1,06 \\
\hline 3 & $1: 2(-1)$ & $60(1)$ & 3,44 & 6,25 & 4,52 & 1,73 \\
\hline 4 & $1: 4(1)$ & $60(1)$ & 4,08 & 8,84 & 8,84 & 0,00 \\
\hline 5 & $1: 3(0)$ & $40(0)$ & 2,74 & 9,32 & 8,85 & 0,47 \\
\hline 6 & $1: 3(0)$ & $40(0)$ & 3,89 & 8,89 & 8,85 & 0,04 \\
\hline 7 & $1: 3(0)$ & $40(0)$ & 2,92 & 8,52 & 8,85 & 0,33 \\
\hline 8 & $1: 1(-1,41)$ & $40(0)$ & 2,44 & 5,08 & 2,70 & 2,38 \\
\hline 9 & $1: 5(+1,41)$ & $40(0)$ & 2,69 & 8,98 & 7,61 & 1,37 \\
\hline 10 & $1: 3(0)$ & $12(-1,41)$ & 3,05 & 7,65 & 7,21 & 0,44 \\
\hline 11 & $1: 3(0)$ & $70(+1,41)$ & 2,06 & 8,90 & 8,06 & 0,84 \\
\hline
\end{tabular}

Para a amostra úmida o ensaio 4 foi o que apresentou maior rendimento em óleo $(4,08 \%)$, na proporção amostra solvente de $1: 4$ e 60 minutos de extração. Entretanto, o ensaio 6 obteve um rendimento próximo (3,89\%), empregando uma menor proporção de amostra e solvente bem como um menor tempo de extração, o que pode minimizar os danos causados em termos de qualidade final do óleo em função do contato direto com o solvente de extração. O menor tempo de extração e a quantidade de solvente reduzida também podem ser relacionados com benefícios ambientais e econômicos devido ao custo e toxicidade dos solventes e pelo menor consumo energético pelos equipamentos envolvidos no processo.

Para a amostra seca, observou-se rendimentos próximos para os ensaios 2 , $4,9,11$ e nos pontos centrais. De maneira geral, a principal diferença entre esses ensaios encontra-se no tempo de extração, de modo que o ensaio 2 apresentou o menor, sendo estas selecionadas como as que melhor favorecem a extração de óleo para a amostra seca. Essa escolha pode ser reforçada pela análise do diagrama de Pareto mostrado na Figura 6, que mostra que apenas a razão amostra:solvente apresentou influência estatisticamente significativa $(p<0,05)$ no processo de extração de óleo e que apesar do tempo de extração apresentar efeito positivo este não teve efeito significativo no processo de extração. 


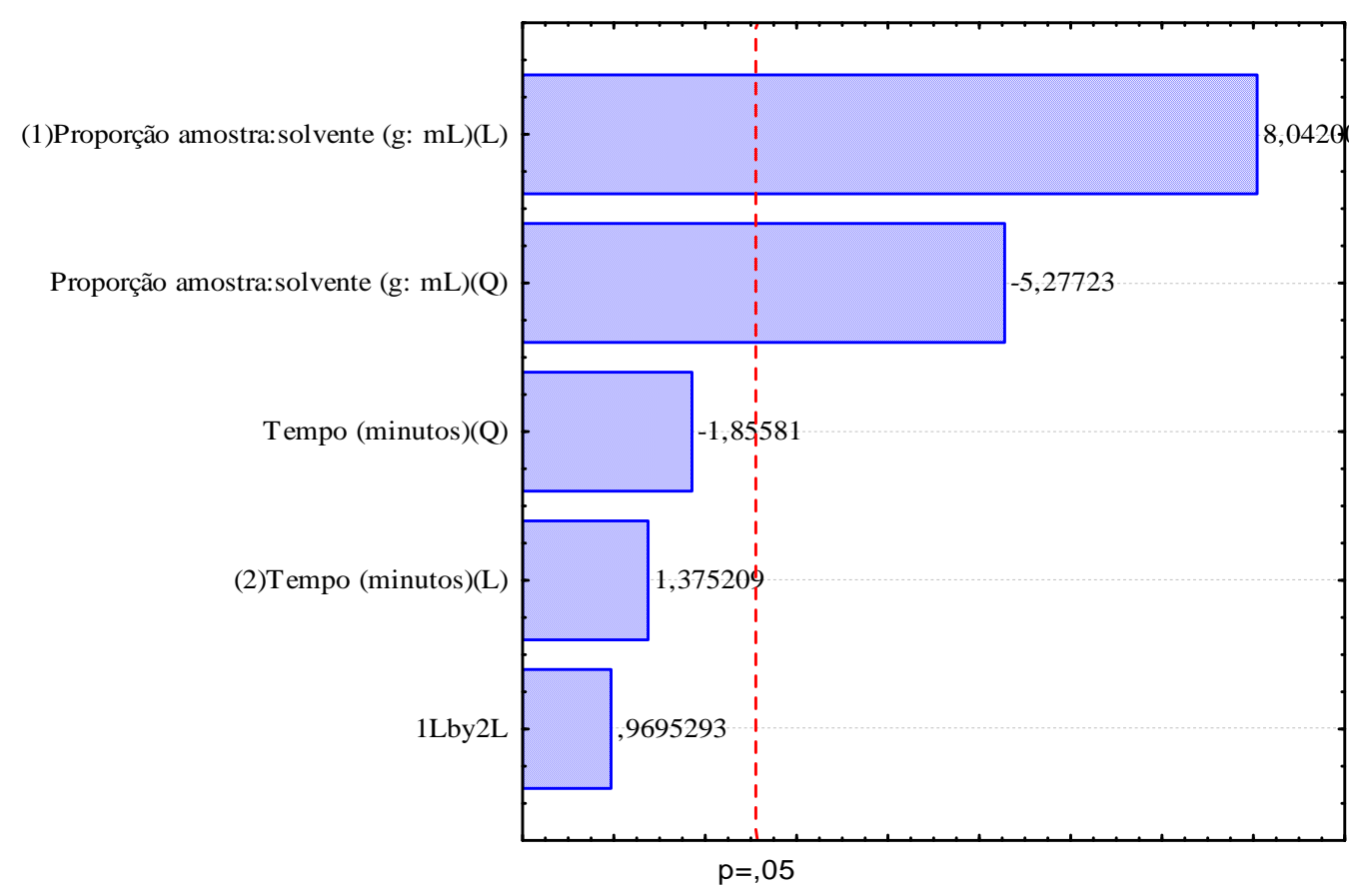

Efeitos estimados (valor absoluto)

FIGURA 6. Diagrama de Pareto mostrando a influência da razão amostra:solvente e do tempo na extração de óleo a partir de resíduo de tambatinga. Fonte: Autores (2018).

Como pelo menos uma das variáveis independentes estudadas apresentou efeitos estatisticamente significativo na extração do óleo de tambatinga, foi possível obter o modelo empírico para estimativa do percentual do rendimento em óleo (Equação 2), sendo que este foi validado estatisticamente $(p<0,05)$ pela análise de variância (ANOVA), conforme pode ser observado na Tabela 5 . Além disso, a qualidade do modelo gerado pode ser observada pelos erros relativamente baixos (coluna 7 da Tabela 5) no cálculo do percentual de óleo predito (coluna 6 da Tabela 5).

$$
\text { Rendimento (\%) }=8,85+1,74 x_{1}-1,86 x_{1}^{2}+0,30 x_{2}-0,61 x_{2}^{2}+0,42 x_{1} x_{2}
$$

TABELA 5. ANOVA para validação do modelo empírico codificado para estimar a percentual de óleo extraído a partir de resíduo de tambatinga

\begin{tabular}{ccccccc}
$\begin{array}{c}\text { Fonte de } \\
\text { Regressão }\end{array}$ & SQ & GL & QM & $\mathbf{F}_{\text {calc }}$ & $\mathbf{F}_{\text {tab }}$ & p-valor \\
\hline Regressão & 17,91 & 5 & 3,58 & 19,06 & 5,05 & 0,004261 \\
\hline Resíduos & 0,94 & 5 & 0,19 & & & \\
\hline Total & 18,85 & 10 & & & $\mathrm{R}^{2}=0,95015$
\end{tabular}

Pela Análise de Variância (ANOVA) verificou-se que o valor de coeficiente de determinação $\left(R^{2}\right)$ foi de 0,95015 , o que sugere que o modelo empírico obtido pode 
explicar aproximadamente $95 \%$ da variação total dos resultados. $O$ valor $F$ representa a razão da soma quadrática média devido à regressão pela soma quadrática média devido ao erro, e indica a significância de cada fator do modelo. $O$ valor de $\mathrm{F}$ calculado foi 19,06 , sendo aproximadamente quatro vezes maior que o $\mathrm{F}$ tabelado $(5,05)$, validando a hipótese que o modelo é estatisticamente significativo.

A Figura 7 mostra a superfície de resposta para a extração de óleo a partir de resíduo de tambatinga em função do tempo e da proporção amostra e solvente, onde é possível observar que foram obtidos os maiores percentuais de óleo na região quando o tempo variou de 20 a 80 minutos e a proporção de amostra e solvente foi de no mínimo 1:4.

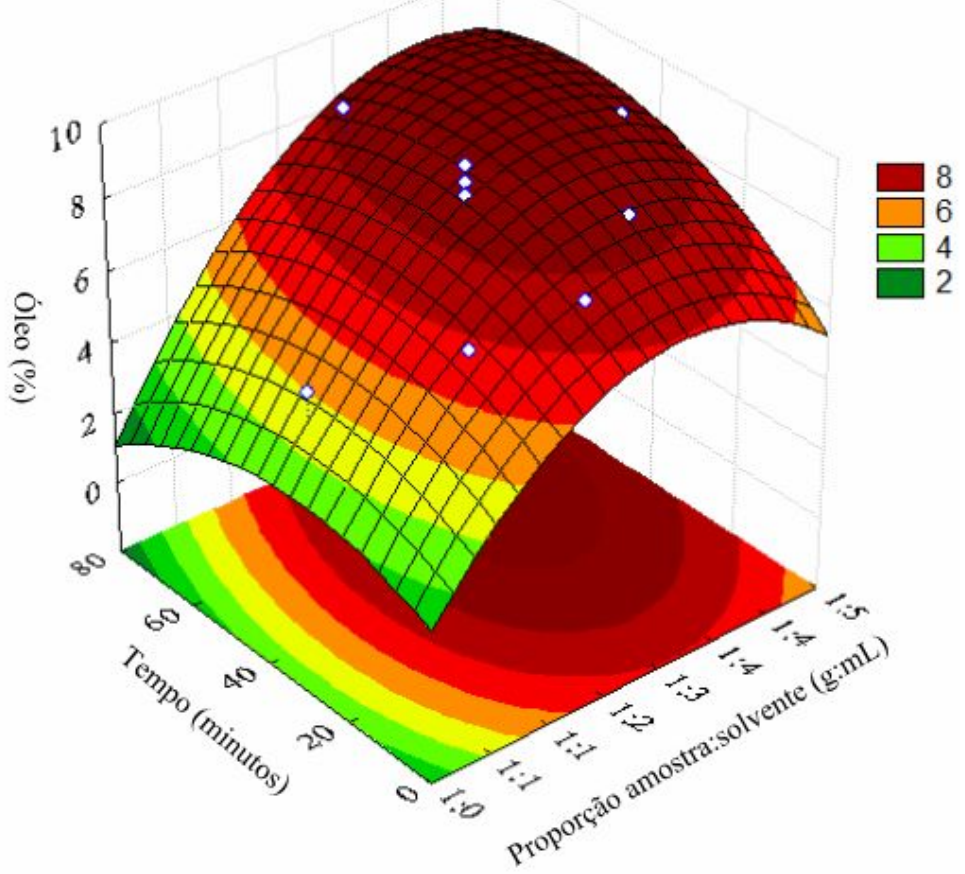

FIGURA 7. Superfície de resposta da extração de óleo do resíduo de tambatinga em função do tempo. Fonte: Autores (2018).

\section{Perfil de ácidos graxos}

O perfil de ácidos graxos do óleo extraído com energia ultrassônica do resíduo de tambatinga encontra-se na Tabela 6.

TABELA 6. Composição de ácidos graxos do óleo extraído do resíduo de tambatinga por extração assistida de energia ultrassônica

\begin{tabular}{lr}
\hline Ácido graxo & $\%$ \\
\hline Ácido Láurico (C12:0) & $0,07 \pm 0,00$ \\
Ácido miristico (C14:0) & $2,27 \pm 0,17$ \\
Ácido pentadecilico (C15:0) & $0,17 \pm 0,01$ \\
Ácido palmítico (C16:0) & $28,33 \pm 0,28$ \\
Ácido margarico (C17:0) & $5,98 \pm 0,34$ \\
Ácido esteárico (C18:0) & $10,48 \pm 0,67$ \\
Ácido araquidico (C20:0) & $0,06 \pm 0,00$ \\
Ácido heneicosanoico (C21:0) & $0,22 \pm 0,01$ \\
\hline
\end{tabular}




\begin{tabular}{|c|c|}
\hline Ácido lignocerico (C24:0) & $0,13 \pm 0,01$ \\
\hline Total de AG saturados & 47,71 \\
\hline Ácido Palmitoléico (C16:1) $\omega-7$ & $0,51 \pm 0,02$ \\
\hline Ácido Heptadecenóico (C16:1) $\omega-9$ & $0,14 \pm 0,00$ \\
\hline Ácido Oléico (C18:1) $\omega-9$ & $36,73 \pm 0,36$ \\
\hline 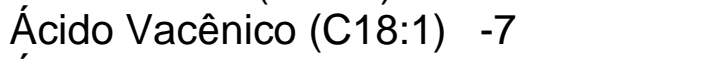 & $2,51 \pm 0,02$ \\
\hline Ácido Gondoico (C20:1) $\omega-9$ & $0,83 \pm 0,04$ \\
\hline Total de AG monoinsaturados & 40,72 \\
\hline Ácido Linoléico (C18:2) $\omega-6$ & $9,56 \pm 0,31$ \\
\hline 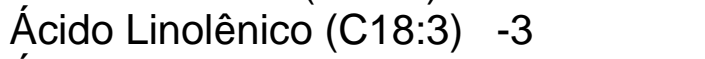 & $0,60 \pm 0,03$ \\
\hline Ácidodihomo-y-linolênico (C20:3) $\omega-6$ & $0,41 \pm 0,03$ \\
\hline Ácido eicosatrienóico (C20:3) $\omega-3$ & $0,53 \pm 0,02$ \\
\hline Ácido araquidônico (C20:4) $\omega-6$ & $0,02 \pm 0,00$ \\
\hline Ácido eicosapentaenoico (C20:5) $\omega-3$ & $0,05 \pm 0,00$ \\
\hline 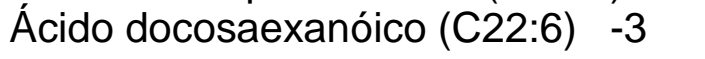 & $0,12 \pm 0,01$ \\
\hline Total de AG poli insaturados & 11,29 \\
\hline Total de AG insaturados & 52,01 \\
\hline Total de $\omega-3$ & 1,30 \\
\hline Total de $\omega-6$ & 9,99 \\
\hline Total de $\omega-7$ & 3,02 \\
\hline Total de $\omega-9$ & 37,70 \\
\hline Razão insaturados/saturados & 1,09 \\
\hline Razão $\omega-6 / \omega-3$ & 7,68 \\
\hline
\end{tabular}

De acordo com os resultados apresentados na Tabela 6 foram identificados 21 tipos de ácidos graxos no óleo extraído do resíduo de tambatinga com predominância do ácido oleico $(36,73 \%)$, ácido palmítico $(28,33 \%)$, ácido esteárico $(10,48 \%)$ e ácido linoleico (9,56\%). Machado et al. (2013) relatam que peixe de água doce apresenta quantidades generosas dos ácidos linoleico e linoênico, o que pode explicar o fato do ácido linoleico estar entre os ácidos graxos predominantes no óleo de resíduo de tambatinga. Além disso, os resultados obtidos são semelhantes aos reportados por Segura (2012) que analisou o perfil de ácidos graxos de três diferentes peixes de água doce (pacu, curimbatá e truta arco íris) e obteve a predominância de ácido oleico, palmítico e linoleico em todos os óleos analisados.

O óleo do resíduo de tambatinga apresentou um total de 47,71\% (ácidos graxos saturados) e 52,01\% (ácidos graxos insaturados), mostrando que o óleo de resíduo de tambatinga pode ser uma alternativa para o consumo de ácidos graxos poli-insaturados. O óleo apresentou uma razão insaturados/saturados de 1,09. Segundo Enser et al. (1998), a relação entre ácidos graxos insaturados/saturados deve ser no mínimo de 0,45 , de maneira que o óleo de resíduo de tambatinga encontra-se dentro desse padrão. Em relação a razão de $\omega-6 / \omega-3$ o valor obtido foi de 7,68, sendo esse valor inferior ao obtido por Segura (2012) para os óleos de truta arco íris e pacu extraídos por congelamento.

\section{CONCLUSÕES}

De acordo com os resultados obtidos no presente estudo, conclui-se na secagem da amostra, quanto mais alta a temperatura, menor foi o tempo necessário para as amostras atingirem a umidade de equilíbrio. $\mathrm{Na}$ modelagem das curvas de 
secagem, o modelo proposto por Page foi a equação que apresentou melhor ajuste aos dados experimentais, em relação a correlação, erro e menor número de parâmetros. Na extração do óleo, apenas a variável razão amostra:solvente apresentou influência significativa no processo de extração de óleo de tambatinga por ultrassom. De modo geral, foi possível extrair óleo com considerável teor de ácidos graxos poli-insaturados empregando a tecnologia ultrassônica.

\section{REFERÊNCIAS}

ABP - Associação Brasileira de Piscicultura. Produção de pescado aumenta em Mato Grosso. 2018. Disponível em: $<$ https://www.sonoticias.com.br/agronoticias/producao-de-pescado-aumenta-emmato-grosso/>

BEVILAQUA, N.C.O. Extração de óleo do resíduo de pacu (Piaractus mesopotamicus) empregando tecnologia ultrassônica. Monografia (Graduação em Engenharia de Alimentos) Universidade do Estado de Mato Grosso - Barra do Bugres, 2015.

DECKER, A.T.; RODRIGUES, E.A.; ALMEIDA, J.C.; QUADRO, M.S.; LEANDRO, D.; ANDREAZZA, R.; BARCELOS, A.A. Impactos ambientais dos resíduos de pescado. Revista Brasileira de Engenharia e Sustentabilidade, v. 2, n. 1, p. 1-10, 2016. Disponível em: <http://dx.doi.org/10.15210/rbes.v2i1.6186>

GONÇALVES, A.A; SOARES, K.M.P. Qualidade e segurança do pescado. Revista Instituto Adolfo Lutz. São Paulo, p. 1-10, 2012. Disponível em: <http://www.ial.sp.gov.br/ial/revista/rev-inst-adolfo-lutz.2012711>

MACHADO, B.A.; REIS, J.H.O.; NUNES, I.L.; PADILHA, F.F.; DRUZIAN, J.I. Determinação do perfil de ácidos graxos por cromatografia gasosa, composição proximal e valor calórico de carne de avestruz (Struthio camellus). Alimentos e Nutrição: Journal of Food and Nutrition., Araraquara, v. 24, n. 2, p. 209-216, 2013. Disponível em: <http:// 200.145.71.150/seer/index.php/alimentos/rt/printerFriendly/209/0>.

MARTINS, G.I.; SECCO, D.; TOKURA, L.K.; BARICCATTI, R.A.; DOLCI,B.D.; SANTOS, R.F. Renewable and Sustainable Energy Reviews. Elsevier. Cascavel, v. 42, p. 234-239, 2014. Disponível em: <https://www.journals.elsevier.com/renewableand-sustainable-energy-reviews>

MONTEIRO, M.L.G. Aproveitamento de resíduos de tilápia (Oreochromis niloticus) para elaboração de novos produtos com valor agregado. 2013. $177 f$. Tese (Doutorado em Higiene Veterinária e Processamento Tecnológico de Produtos de Origem Animal) - Universidade Federal Fluminense- RJ.

SEGURA, J.G. Extração e caracterização de óleos de resíduos de peixes de água doce. Dissertação (Mestrado em Ciências). Universidade de São Paulo. Pirassununga, 2012.

TSUKUI, A; REZENDE, C.M. Extração Assistida por Micro-ondas e Química Verde. Revista Virtual de Química, v 6, p 1713-1725, 2014. Disponível em:

< http://dx.doi.org/10.5935/1984-6835.20140111> 